\title{
Wound infiltration with ropivacaine as an adjuvant to patient controlled analgesia for transforaminal lumbar interbody fusion: a retrospective study
}

Kunpeng Li, Changbin Ji, Dawei Luo, Hongyong Feng, Keshi Yang and Hui Xu*

\begin{abstract}
Background: Surgical procedure usually causes serious postoperative pain and poor postoperative pain management negatively affects quality of life, function and recovery time. We aimed to investigate the role of wound infiltration with ropivacaine as an adjuvant to patient controlled analgesia (PCA) in postoperative pain control for patients undergoing transforaminal lumbar interbody fusion.
\end{abstract}

Methods: One hundred twelve patients undergoing lumbar fusion were retrospectively reviewed and divided into two groups (ropivacaine and control groups) according to whether received wound infiltration with ropivacaine or not. Visual Analogue Scale (VAS) score, analgesics consumption, number of patients requiring rescue analgesic, hospital duration and incidence of complications were recorded. Surgical trauma was assessed using operation time, intraoperative blood loss and incision length.

Results: The amount of sufentanil consumption in ropivacaine group at $4 \mathrm{~h}$ postoperatively was lower than that of control group $(24.5 \pm 6.0 \mu \mathrm{g}$ vs $32.1 \pm 7.0 \mu \mathrm{g}, P<0.001)$ and similar results were observed at $8,12,24,48$ and $72 \mathrm{~h}$ postoperatively $(P<0.001)$. Fewer patients required rescue analgesia within 4 to $8 \mathrm{~h}$ postoperatively in ropivacaine group (10/60 vs 19/52, $P=0.017$ ). Length of postoperative hospital durations were shorter in patients receiving ropivacaine infiltration compared to control cohorts ( $6.9 \pm 0.9$ days vs $7.4 \pm 0.9$ days, $P=0.015)$. The incidence of PONV in ropivacaine group was lower than that in control group ( $40.4 \%$ vs $18.3 \%, P=0.01)$. However, VAS scores were similar in two groups at each follow-up points postoperatively, and no difference was observed $(P>0.05)$.

Conclusion: Wound infiltration with ropivacaine effectively reduces postoperative opioid consumption and PONV and may be a useful adjuvant to PCA to improve recovery for patients undergoing lumbar spine surgery.

Keywords: Wound infiltration, Ropivacaine, Pain management, PCA, Transforaminal lumbar interbody fusion

*Correspondence: xuhspine@163.com

Department of Orthopaedics, Liaocheng People's Hospital, No 67

Dongchang West Road, Liaocheng City 252000, Shandong Province, China

(c) The Author(s). 2020 Open Access This article is licensed under a Creative Commons Attribution 4.0 International License, which permits use, sharing, adaptation, distribution and reproduction in any medium or format, as long as you give appropriate credit to the original author(s) and the source, provide a link to the Creative Commons licence, and indicate if changes were made. The images or other third party material in this article are included in the article's Creative Commons licence, unless indicated otherwise in a credit line to the material. If material is not included in the article's Creative Commons licence and your intended use is not permitted by statutory regulation or exceeds the permitted use, you will need to obtain permission directly from the copyright holder. To view a copy of this licence, visit http://creativecommons.org/licenses/by/4.0/ The Creative Commons Public Domain Dedication waiver (http://creativecommons.org/publicdomain/zero/1.0/) applies to the data made available in this article, unless otherwise stated in a credit line to the data. 


\section{Background}

Transforaminal lumbar interbody fusion (TLIF) has been widely used in treatment of lumbar degenerative spine disorders, and achieved good clinical results and high patient satisfaction $[1,2]$. It can decompress the nerve roots, immobilize the instrumented segments and provide stability of spine. Despite its good outcome, surgical procedure usually causes serious postoperative pain and poor pain management negatively affects quality of life, function, and recovery [3].

Traditionally, patient-controlled analgesia (PCA) has been identified as effective in postoperative pain management and is the most frequently used analgesic method for spine surgery $[4,5]$. However, the main drug used is opioid analgesics, which have severe side effects including nausea or vomiting, confusion, urinary retention, sedation, respiratory depression, and pruritus [6]. Therefore, finding other analgesic strategies with fewer potentially adverse effects will be beneficial for patients suffering from postoperative pain.

In recent years, wound infiltration with local anesthetics has become an attractive method in postoperative analgesia because of its safety, simplicity and low-cost [7, 8]. As a local anesthetic, ropivacaine is a propyl analog of bupivacaine with longer duration of action and much safer cardiotoxicity profile. Several reports $[9,10]$ have confirmed that wound infiltration with ropivacaine could significantly reduce postoperative pain, mitigate supplemental analgesic demand as well as curtail hospital stay following some surgeries, such as joint replacement, abdominal surgeries, and cesarean deliveries.

With the ideal analgesic modality for lumbar fusion surgery still unknown and possibly simpler alternatives to local infiltration analgesia gaining popularity, it is imperative to clarify the role of wound infiltration with ropivacaine in managing postoperative pain after this procedure. We hypothesized that wound infiltration with ropivacaine as an adjuvant to PCA for patients undergoing TLIF is more effective than PCA alone, resulting in lower postoperative pain scores, less consumption of opioid medications and lower incidence of postoperative nausea and vomiting (PONV) compared with PCA alone.

\section{Methods}

\section{Patient population}

This retrospective cohort study was conducted in Liaocheng People's Hospital. All patients were identified to undergo single-level TLIF procedure with a single surgeon between January 2016 and December 2018. The inclusion criteria were as follow: age 18-65 years, primary diagnosis of lumbar disc herniation, lumbar spinal stenosis and lumbar degenerative spondylolisthesis (grade 1), single level TLIF (L3/4, L4/5 or L5/S1), American
Society of Anesthesiologists (ASA) grade I to II. Patients were excluded according to the exclusion criteria: allergic to ropivacaine, preoperative opioid consumption in last 3 months, and history of spine surgery.

Enrolled patients were divided into two groups, ropivacaine group and control group. Each patient provided written informed consent before enrollment. The study was approved by the Ethics Committee of Liaocheng People's Hospital.

\section{Surgical procedure}

The procedure was performed as described by Ge [11]. All procedures were carried out under controlled general anesthesia with endotracheal intubation. Each patient was positioned prone on a radiolucent operating table after induction of general anesthesia. Radiographs were used to check the operation level. A midline approach was used to expose the lamina and spinous processes. Bilateral pedicle screws were placed and a rod was sited using special persuaders. The laminectomy and facetectomy were then performed at the level. The cartilaginous material was removed from the endplates using the scraper. The autogenous morselized bone from the laminae and processus articularis was placed into the anterior intervertebral space. This was followed by the implantation of cage plus autogenous bone. The wound was copiously irrigated and closed in layers. Routine monitoring included electrocardiography, pulse oximetry, blood pressure, and arterial blood gas analysis. All patients received general anesthesia with $0.1 \%$ propofol, dexmethetomedine, fentanyl, remifentanil and cisatracurium. No preemptive scheduled analgesic regimen was employed.

\section{Wound infiltration with ropivacaine}

Just before closure, $10 \mathrm{ml}$ ropivacaine (concentration: $0.75 \%$ ) was infiltrated in paravertebral muscles, subcutaneous, and cutaneous tissue along each side of the wound edges. At the end of surgery, patients were turned to supine position, and extubated successfully on the table. Once awake and responded to verbal commands, patients were transferred to the post-anesthesia care unit (PACU). After PACU, patients were transferred to spine ward for further monitoring and recovery care.

\section{Postoperative management}

All patients received intravenous PCA with $0.8 \mu \mathrm{g} / \mathrm{ml}$ of sufentanil for $72 \mathrm{~h}$. The sufentanil was administrated via PCA pump at a bolus of $2 \mathrm{ml}(1.6 \mu \mathrm{g})$ with a 5 min lockout time and the maximum dosage was $12.8 \mu \mathrm{g}$ per hour. Flurbiprofen axetil was injected as a rescue analgesic when requested by patients with visual analogue scale (VAS) scores $\geq 5$. 
Patients were routinely administered prophylactic antibiotics for $24 \mathrm{~h}$ and encouraged to start out-of-bed activities with braces within 3 days after surgery. Mechanical thomboprophylaxis was given to prevent phlebothrombosis of both legs. Since discharge from the hospital, all patients were clinically and radiologically assessed in outpatient clinic every 3 months.

\section{Observation index}

Primary outcome was total sufentanil consumption over the first $72 \mathrm{~h}$. The sufentanil consumption can be calculated by multiplying the volume by the concentration $(0.8 \mu \mathrm{g} / \mathrm{ml}$, total $200 \mu \mathrm{g}$ sufentanil in $250 \mathrm{ml}$ saline). The volume of saline was shown in the PCA pump. Secondary outcome measures were VAS scores, number of patients requiring flurbiprofen axetil as analgesic rescue and incidence of complications including PONV and wound infection. Operation time, intraoperative blood loss, incision length and length of postoperative hospital duration were also recorded in the data.

\section{Sample size and statistical analyses}

The sample size was determined for the primary outcome measure. According to previous study [12], a difference of more than10ug in sufentanil consumption at $24 \mathrm{~h}$ after surgery between groups was considered clinically relevant. Under the assumption that the standard deviation is $16 \mu \mathrm{g}$, a sample size of 41 per group was determined (power $=80 \%, p=0.05$ ). For the secondary outcome of VAS score, sample size estimates were also considered. On the basis of the data from clinical practice and the study by Elder et al. [13], the standard deviation for the VAS was assumed to be 2.0 and a sample size of 38 patients per group would provide statistical power of $80 \%$ to detect a difference between groups of 1.3. Additionally, we reviewed several similar reports [14, 15] and found that the number of treated subjects was approximately 40 to 50 . Therefore, we determined that a total of 50 patients per group were enrolled. The power was 0.872 according to primary outcome data mentioned above $(n=$ $50, \sigma=16, \delta=10, \alpha=0.05)$. The sample size and power analysis were performed using Power and Sample Size Calculation version 3.1.6.

The SPSS 22.0 statistical package (SPSS, Chicago, IL, U.S.A.) was used for statistical analyses. Continuous data were presented as the mean \pm standard deviation and analyzed using two-sample $\mathrm{t}$ test and ANOVA analysis. Chi square test was performed to analyze count data. For all analyses, a $P$ value $<0.05$ was considered statistically significant.

\section{Results}

This clinical trial enrolled 112 patients undergoing single-level TLIF procedure, 60 patients who received wound infiltration with ropivacaine in ropivacaine group and 52 without ropivacaine infiltration in control group.

Table 1 Characteristics of the patient cohort in two groups

\begin{tabular}{|c|c|c|c|}
\hline Parameter & Ropivacaine group & Control group & $P$ value \\
\hline Number of patients & 60 & 52 & \\
\hline Age (years) & $57.9 \pm 7.7(41-73)$ & $\begin{array}{l}56.9 \pm 7.5 \\
(42-72)\end{array}$ & 0.529 \\
\hline Gender, males/females & $39 / 21$ & $35 / 17$ & 0.799 \\
\hline Weight (kg) & $67.2 \pm 8.2$ & $66.3 \pm 8.9$ & 0.581 \\
\hline Height (cm) & $167.9 \pm 6.5$ & $168.8 \pm 6.5$ & 0.472 \\
\hline BMI $\left(\mathrm{kg} / \mathrm{m}^{2}\right)$ & $23.8 \pm 2.0$ & $23.2 \pm 2.1$ & 0.134 \\
\hline Diagnosis & & & 0.775 \\
\hline LDH & 26 & 32 & \\
\hline LSS & 17 & 16 & \\
\hline LDS & 9 & 12 & \\
\hline Operation level & & & 0.790 \\
\hline $\mathrm{L} 3 / 4$ & 6 & 5 & \\
\hline$\llcorner 4 / 5$ & 25 & 32 & \\
\hline $\mathrm{L} 5 / \mathrm{S} 1$ & 21 & 23 & \\
\hline Operation time (min) & $103.1 \pm 15.2$ & $106.5 \pm 17.1$ & 0.260 \\
\hline Intraoperative blood loss (ml) & $250.6 \pm 38.6$ & $258.1 \pm 39.7$ & 0.314 \\
\hline Incision length (cm) & $6.2 \pm 0.7$ & $6.1 \pm 0.8$ & 0.299 \\
\hline Postoperative hospital duration (day) & $6.9 \pm 0.9$ & $7.4 \pm 0.9$ & 0.015 \\
\hline
\end{tabular}

LDH Lumbar disc herniation, LSS Lumbar spinal stenosis, LDS Lumbar degenerative spondylolisthesis 
Patients' demographics and basic characteristics, including age, gender, weight, height, body mass index (BMI), primary diagnosis and operation level were shown in the Table 1, and no significant difference was observed between two groups.

\section{Operation index and hospital duration}

The mean operation time was $103.1 \pm 15.2 \mathrm{~min}$ and $106.5 \pm 17.1 \mathrm{~min}$ in ropivacaine and control groups respectively, and no difference was found $(P=0.26)$. There was also no difference in incision length and intraoperative blood loss between two groups $(P=0.299$ and $P=$ 0.314) (Table 1).

For patients receiving ropivacaine infiltration, length of postoperative hospital duration was $6.9 \pm 0.9$ days, which was shorter than that of control cohort $(7.4 \pm 0.9$ days), and significant difference was detected between two groups $(P=0.015)$ (Table 1$)$.

\section{Postoperative analgesics consumption}

The amount of sufentanil consumption at $4 \mathrm{~h}$ postoperatively in ropivacaine group was lower than that in control group $(P<0.001)$. Significant difference was also found in the cumulative sufentanil consumption between two groups at $8,12,24,48$ and $72 \mathrm{~h}$ after surgery $(P<0.001)$.

Patients in the ropivacaine group consumed less sufentanil than those in the control group within 4 to $8 \mathrm{~h}$ postoperatively $(P<0.001)$. Similar results were observed
Table 2 The administration of flurbiprofen axetil in two groups

\begin{tabular}{llll}
\hline Period & Ropivacaine group & Control group & $\boldsymbol{P}$ value \\
\hline First 4h & $5 / 60$ & $8 / 52$ & 0.245 \\
From 4 to 8h & $10 / 60$ & $19 / 52$ & 0.017 \\
From 8 to 12 h & $6 / 60$ & $11 / 52$ & 0.101 \\
\hline
\end{tabular}

within 8 to 12 hours and 12 to $24 \mathrm{~h}$ postoperatively $(P<$ 0.001 and $P=0.001)$. However, no difference was detected within 24 to $48 \mathrm{~h}$ and 48 to $72 \mathrm{~h}$ postoperatively $(P=0.276$ and $P=0.547)$ (Fig. 1).

There were five patients who required flurbiprofen axetil as rescue in the ropivacaine group and eight in the control group within first $4 \mathrm{~h}$ postoperatively, and no difference was found $(P=0.245)$. However, fewer patients in ropivacaine group needed analgesic rescue within 4 to $8 \mathrm{~h}$ postoperatively compared to control group $(P=$ $0.017)$. Within 8 to $12 \mathrm{~h}$ postoperatively, no difference was found between two groups $(P=0.101)$ (Table 2$)$.

\section{Pain evaluation}

Average VAS scores at $4 \mathrm{~h}$ postoperatively was $3.7 \pm 1.5$ points in ropivacaine group and $3.7 \pm 1.3$ points in control group, and no difference was observed $(P=0.808)$. Similar results were shown between the ropivacaine and control groups at $8 \mathrm{~h}(4.1 \pm 1.3$ vs $4.3 \pm 1.1, P=0.568)$, $12 \mathrm{~h}(4.3 \pm 1.3$ vs $4.4 \pm 1.2, P=0.655), 24 \mathrm{~h}(3.3 \pm 1.1$ vs $3.4 \pm 1.0, P=0.822), 48 \mathrm{~h}(2.4 \pm 0.6$ vs $2.3 \pm 0.5, P=0.700)$

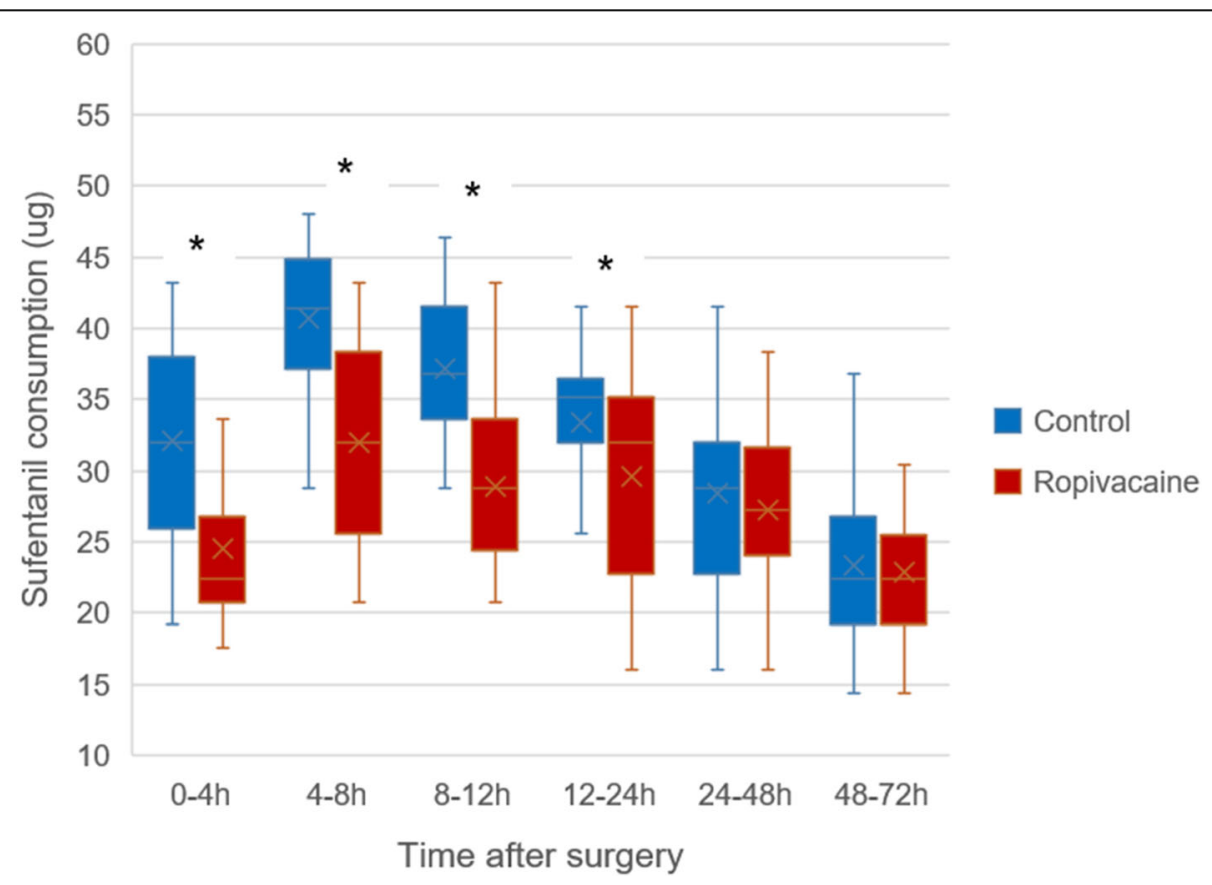

Fig. 1 Boxplot showing sufentanil consumption in the postoperative period for two groups. The boxes indicate the interquartile range, the crosses within the boxes indicate the median, and the whiskers indicate the range. The asterisks indicate significance $(P<0.05)$. $h=$ hours postoperatively 


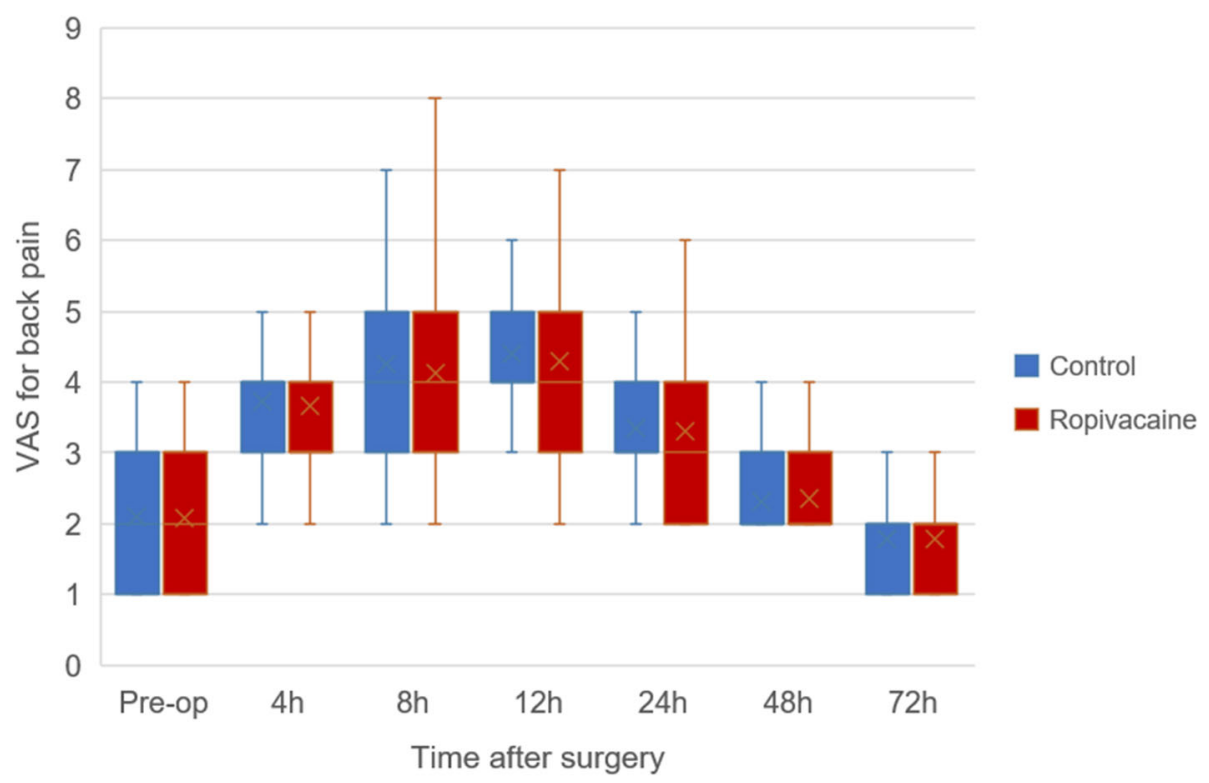

Fig. 2 Boxplot showing VAS scores for back pain over the first $72 \mathrm{~h}$ postoperatively for two groups. The boxes indicate the interquartile range, the crosses within the boxes indicate the median, and the whiskers indicate the range. No significant difference was observed at each time between two groups $(P>0.05)$. $h=$ hours postoperatively

and $72 \mathrm{~h}(1.8 \pm 0.6$ vs $1.8 \pm 0.6, P=0.964)$ postoperatively (Fig. 2).

\section{Complications}

The incidence of PONV in the ropivacaine group was lower than that in the control group $(18.3 \%$ vs $40.4 \%$, $P=0.010)$. Only one patient had wound infection in each group and no difference was detected $(P=0.919$, Table 3). These two patients recovered after routine antibiotic treatment and dressing change. No clinical deterioration, permanent morbidity or mortality occurred in this study. There was also no hardware failure, nerve root injury, cerebrospinal fluid leakage, and adjacent segment disc herniation over the follow-up.

\section{Discussion}

In this study, we adopted wound infiltration with ropivacaine as an adjuvant to PCA in TLIF procedure to assess its efficacy in postoperative pain management. Results showed better outcomes in patients who received the wound infiltration with ropivacaine. It reduced the consumption of opioid drugs via PCA after TLIF procedure and decreased the number of patients who required rescue analgesia, while achieving similar pain relief. The

Table 3 The incidence of complications in two groups

\begin{tabular}{llll}
\hline Complication & Ropivacaine group & Control group & $\boldsymbol{P}$ value \\
\hline PONV & $11 / 60$ & $21 / 52$ & 0.010 \\
wound infection & $1 / 60$ & $1 / 52$ & 0.919 \\
\hline
\end{tabular}

data further indicated a lower incidence of PONV and a shorter hospital duration in the ropivacaine group.

Currently, PCA is the most widely used approach to manage postoperative pain after spine surgery. However, the use of opioids in PCA is often associated with adverse effects. So multimodal pain management is recommended in order to reduce opioid-related adverse effects. Since Mullen and Cook first demonstrated the use of wound infiltration with local anesthetics in spine surgery in 1979 [16], a few literatures reported the application of wound infiltration with local anesthetics in several surgical procedures. Koehler [15] performed a randomized controlled trial and reported that surgicalsite injection with a multimodal cocktail could reduce narcotic utilization and provide improved pain control, with no adverse effects attributable to the local injection. Similarly, in a retrospective study of patients undergoing thoracolumbar junction fracture surgery, Swennen [17] found that local infiltration analgesia had a reduction of VAS and morphine consumption in postoperative pain control. Another two studies $[13,18]$ on the continuous analgesic infusion also demonstrated better outcomes in managing postoperative pain with less opioid use and lower pain scores.

The main outcome measures in this study were visual analogue pain score and opioid usage. In the current study, results showed patients receiving ropivacaine infiltration reported similar VAS scores and less sufentanil consumption via PCA at each follow-up point within 72 $\mathrm{h}$ after surgery, which was not completely consistent with previous reports. Although similar VAS score was 
reported in two groups, less opioid use was another important indicator that reflected the decreased postoperative pain in ropivacaine group. We further found that periodic consumption of sufentanil in the ropivacaine patients was less than that of the control group only within $24 \mathrm{~h}$ postoperatively. We attributed this to that the single dose of ropivacaine was injected in our study and its duration acted within $24 \mathrm{~h}$ [19]. This also indicated that the decreased opioid consumption would be associated with the use of wound infiltration with ropivacaine.

There are multiple choices for local anesthetic. Bupivacaine and ropivacaine are commonly used after surgery, but ropivacaine is reported to have a lower risk of cardiovascular or central nervous system toxicity [20]. Elder [18] used an elastomeric pump to infuse $0.5 \%$ bupivacaine into the wound for pain control in lumbar spinal fusion and data showed that continuous bupivacaine infusion resulted in lower pain scores and narcotic use with lower incidence of nausea and vomiting and decreased times to mobility and functional independence. He also considered that a single intraoperative dose of local anesthetic does not provide adequate postoperative pain control because of the short period of analgesic effect inherent to local anesthetics. But Sun's study reported that local wound infiltration with single dose of ropivacaine after open hepatectomy could improve postoperative pain relief, reduce surgical stress response, and accelerate postoperative recovery. Our study confirmed that intraoperative wound infiltration with single dose of ropivacaine could provide pain relief and reduce opioid use within postoperative $24 \mathrm{~h}$. However, a small number of studies have demonstrated contrary results showing wound infiltration with ropivacaine does not offer significant postoperative pain relief [21, 22]. Kakagia [23] compared local infiltration of ropivacaine with levobupivacaine in a randomized controlled trial and found that in terms of intensity and duration of analgesia, ropivacaine was less effective than levobupivacaine in reducing postoperative pain associated with mini abdominoplasty.

PONV is a common side effect of opioid-based intravenous PCA. Previous studies reported that a logarithmic dose response relationship between the use of postoperative opioids and PONV [24, 25]. The decreased rate of PONV that was observed in ropivacaine group may be related to less opioid consumption consumed by patients receiving wound infiltration with ropivacaine, which was similar to Li's report from a randomized controlled trial [26]. PONV was also an unpleasant side effect feared by many patients during acute postoperative course, which can also cause dehydration, electrolyte imbalance, postoperative bleeding, wound dehiscence, and pulmonary aspiration $[27,28]$. Hence, in addition to improving patient experience, the lower rate of PONV may also contribute to shorter length of hospital duration.
Effective pain management is now recognized as one of the three fundamental aspects of enhanced recovery after surgery [29]. In this trial, we investigated the role of wound infiltration with ropivacaine in postoperative hospital duration, which was reported to be a better indicator of patient recovery [30]. Patients who received wound infiltration with ropivacaine as an adjuvant to PCA had shorter length of postoperative hospital duration compared to those receiving PCA alone. These suggested that the use of ropivacaine infiltration may promote enhanced recovery and further decrease postoperative hospital stay in patients undergoing TLIF, which may be attributed to the decreased opioid use of PCA after wound infiltration with ropivacaine.

There are some limitations to this study, which may impair the ability to assess the effect of wound infiltration with ropivacaine on postoperative pain management. First, this was a retrospective cohort study in a single center, not randomized and blind, which may introduce the possibility of selection bias. Second, we did not analyze the difference of time to administrate rescue analgesic. Moreover, this study enrolled a small patient population. In the future, prospectively randomized controlled study, including more patients in multicenter will be performed to properly evaluate the role of wound infiltration with ropivacaine as an adjuvant to PCA in postoperative pain management.

\section{Conclusion}

Results of this study indicate that wound infiltration with ropivacaine effectively reduces postoperative opioid consumption and PONV and may be a useful adjuvant to PCA to improve recovery for patients undergoing lumbar spine surgery.

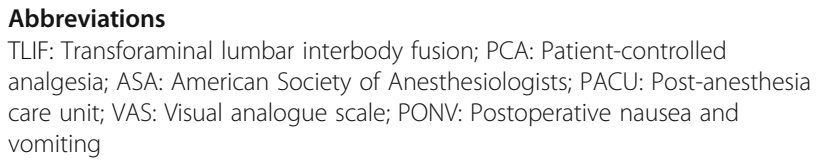
drafting of manuscript and revised the manuscript. CBJ and FHY contributed to the data analysis and interpretation. LDW and YKS data collection and analysis. All authors have read and approved the final manuscript.

\section{Funding}

This study was supported by Natural Science Foundations of Shandong Province (ZR2017MH112). The funders had no role in study design, data collection and analysis, preparation of the manuscript.

Availability of data and materials

All relevant data was presented within the manuscript and the datasets used and/or analyzed during the current study are available from the corresponding author on reasonable request. 


\section{Ethics approval and consent to participate}

This study was approved by ethics committee of Liaocheng People's Hospital. Each patient was fully informed the contents of this study, consented to participate in this study and provided informed consents form.

\section{Consent for publication}

Not applicable.

\section{Competing interests}

The authors declare that they have no competing interests.

Received: 5 August 2020 Accepted: 15 November 2020 Published online: 18 November 2020

\section{References}

1. Qin R, Liu B, Zhou P, et al. Minimally invasive versus traditional open transforaminal lumbar interbody fusion for the treatment of single-level spondylolisthesis grades 1 and 2: a systematic review and meta-analysis. World Neurosurg. 2018. https://doi.org/10.1016/..wneu.2018.10.202.

2. de Kunder SL, van Kuijk SMJ, Rijkers K, et al. Transforaminal lumbar interbody fusion (TLIF) versus posterior lumbar interbody fusion (PLIF) in lumbar spondylolisthesis: a systematic review and meta-analysis. Spine J. 2017:17:1712-21. https://doi.org/10.1016/j.spinee.2017.06.018.

3. Kehlet H, Dahl JB. Anaesthesia, surgery, and challenges in postoperative recovery. Lancet (London, England). 2003;362:1921-8. https://doi.org/10. 1016/s0140-6736(03)14966-5.

4. Gessler F, Mutlak H, Tizi K, et al. Postoperative patient-controlled epidural analgesia in patients with spondylodiscitis and posterior spinal fusion surgery. J Neurosurg Spine. 2016;24:965-70. https://doi.org/10.3171/2015.8 Spine15415.

5. Toktas ZO, Konakci M, Yilmaz B, et al. Pain control following posterior spine fusion: patient-controlled continuous epidural catheter infusion method yields better post-operative analgesia control compared to intravenous patient controlled analgesia method. A retrospective case series. European Spine J. 2016;25:1608-13. https://doi.org/10.1007/s00586-016-4507-3.

6. Bohl DD, Louie PK, Shah N, et al. Multimodal Versus Patient-Controlled Analgesia After an Anterior Cervical Decompression and Fusion. Spine. 2016; 41:994-8. https://doi.org/10.1097/brs.0000000000001380.

7. Mont MA, Beaver WB, Dysart SH, Barrington JW, Del Gaizo DJ. Local Infiltration Analgesia With Liposomal Bupivacaine Improves Pain Scores and Reduces Opioid Use After Total Knee Arthroplasty: Results of a Randomized Controlled Trial. J Arthroplasty. 2018;33:90-6. https://doi.org/10.1016/j.arth. 2017.07.024

8. Affas F. Local infiltration analgesia in knee and hip arthroplasty efficacy and safety. Scand J Pain. 2016;13:59-66. https://doi.org/10.1016/.spain.2016.05.041.

9. Cha SM, Kang H, Baek CW, et al. Peritrocal and intraperitoneal ropivacaine for laparoscopic cholecystectomy: a prospective, randomized, double-blind controlled trial. J Surg Res. 2012;175:251-8. https://doi.org/10.1016/j.jss.2011. 04.033.

10. O'Neill P, Duarte F, Ribeiro I, Centeno MJ, Moreira J. Ropivacaine continuous wound infusion versus epidural morphine for postoperative analgesia after cesarean delivery: a randomized controlled trial. Anesthesia Analgesia. 2012; 114:179-85. https://doi.org/10.1213/ANE.0b013e3182368e87.

11. Ge DH, Stekas ND, Varlotta CG, et al. Comparative Analysis of Two Transforaminal Lumbar Interbody Fusion Techniques: Open TLIF Versus Wiltse MIS TLIF. Spine. 2018. https://doi.org/10.1097/brs.0000000000002903.

12. Li K, Li H, Luo D, et al. Efficacy of local infiltration analgesia with ropivacaine for postoperative pain management in cervical laminoplasty: a retrospective study. Sci Rep. 2020;10:4217. https://doi.org/10.1038/s41598-020-61229-2.

13. Elder JB, Hoh DJ, Liu CY, Wang MY. Postoperative continuous paravertebral anesthetic infusion for pain control in posterior cervical spine surgery: a case-control study. Neurosurgery. 2010;66:99-106; discussion 106-107. https://doi.org/10.1227/01.Neu.0000349208.87863.B3.

14. Johnson RL, Amundson AW, Abdel MP, et al. Continuous Posterior Lumbar Plexus Nerve Block Versus Periarticular Injection with Ropivacaine or Liposomal Bupivacaine for Total Hip Arthroplasty: A Three-Arm Randomized Clinical Trial. J Bone Joint Surg Am Vol. 2017;99:1836-45. https://doi.org/10. 2106/jbjs.16.01305

15. Koehler D, Marsh JL, Karam M, Fruehling C, Willey M. Efficacy of SurgicalSite, Multimodal Drug Injection Following Operative Management of
Femoral Fractures: A Randomized Controlled Trial. J Bone Joint Surg Am Vol. 2017;99:512-9. https://doi.org/10.2106/jbjs.16.00733.

16. Mullen JB, Cook WA Jr. Reduction of postoperative lumbar hemilaminectomy pain with Marcaine. Technical note. J Neurosurg. 1979;51: 126-7. https://doi.org/10.3171/jns.1979.51.1.0126.

17. Swennen C, Bredin S, Eap C, Mensa C, Ohl X, Girard V. Local infiltration analgesia with ropivacaine in acute fracture of thoracolumbar junction surgery. Orthopaedics Traumatol Surg Res. 2017;103:291-4. https://doi.org/ 10.1016/j.otsr.2016.11.012.

18. Elder JB, Hoh DJ, Wang MY. Postoperative continuous paravertebral anesthetic infusion for pain control in lumbar spinal fusion surgery. Spine. 2008;33:210-8. https://doi.org/10.1097/BRS.0b013e318160447a.

19. Riff C, Guilhaumou R, Marsot A, et al. Ropivacaine Wound Infiltration for Pain Management After Breast Cancer Mastectomy: A Population Pharmacokinetic Analysis. Clin Pharmacol Drug Dev. 2018. https://doi.org/10. 1002/cpdd.452.

20. Zink W, Graf BM. Benefit-risk assessment of ropivacaine in the management of postoperative pain. Drug Safety. 2004;27:1093-114. https://doi.org/10. 2165/00002018-200427140-00003.

21. Braito M, Dammerer D, Schlager A, Wansch J, Linhart C, Biedermann R. Continuous wound infiltration after hallux Valgus surgery. Foot Ankle Int. 2018:39:180-188.10.1177/1071100717736292.

22. Beaussier M, Parc Y, Guechot J, Cachanado M, Rousseau A, Lescot T. Ropivacaine preperitoneal wound infusion for pain relief and prevention of incisional hyperalgesia after laparoscopic colorectal surgery: a randomized, triple-arm, double-blind controlled evaluation vs intravenous lidocaine infusion, the CATCH study. Colorectal Dis. 2018;20:509-19. https://doi.org/10. 1111/codi.14021.

23. Kakagia DD, Fotiadis S, Tripsiannis G, Tsoutsos D. Postoperative analgesic effect of locally infiltrated levobupivacaine in fleur-de-Lys abdominoplasty. Aesthetic Plastic Surg. 2007;31:128-32. https://doi.org/10.1007/s00266-0060187-4.

24. Yi MS, Kang H, Kim MK, et al. Relationship between the incidence and risk factors of postoperative nausea and vomiting in patients with intravenous patient-controlled analgesia. Asian J Surg. 2018;41:301-6. https://doi.org/10. 1016/j.asjsur.2017.01.005

25. Gan TJ. Risk factors for postoperative nausea and vomiting. Anesthesia Analgesia. 2006;102:1884-98. https://doi.org/10.1213/01.Ane.0000219597. $16143.4 \mathrm{~d}$.

26. Li J, Yang JS, Dong BH, Ye JM. The Effect of Dexmedetomidine Added to Preemptive Ropivacaine Infiltration on Postoperative Pain after Lumbar Fusion Surgery: A Randomized Controlled Trial. Spine. 2019. https://doi.org/ 10.1097/brs.00000000000003096.

27. Chae D, Kim SY, Song Y, et al. Dynamic predictive model for postoperative nausea and vomiting for intravenous fentanyl patient-controlled analgesia. Anaesthesia. 2020;75:218-26. https://doi.org/10.1111/anae.14849.

28. Singh K, Bohl DD, Ahn J, et al. Multimodal Analgesia Versus Intravenous Patient-Controlled Analgesia for Minimally Invasive Transforaminal Lumbar Interbody Fusion Procedures. Spine (Phila Pa 1976). 2017;42:1145-50. https://doi.org/10.1097/brs.0000000000001992.

29. Nimmo SM, Foo ITH, Paterson HM. Enhanced recovery after surgery: Pain management. J Surg Oncol. 2017;116:583-91. https://doi.org/10.1002/jso. 24814.

30. Rao Z, Zhou H, Pan X, et al. Ropivacaine wound infiltration: a fast-track approach in patients undergoing thoracotomy surgery. J Surg Res. 2017;220: 379-84. https://doi.org/10.1016/j.jss.2017.05.082.

\section{Publisher's Note}

Springer Nature remains neutral with regard to jurisdictional claims in published maps and institutional affiliations. 